\title{
Amy Winehouse e a casa dos mortos: a noção de genialidade no Romantismo Alemão
}

\author{
Sérgio Murilo Rodrigues*
}

\begin{abstract}
Resumo
Criar significa destruir também. A genialidade cobra um preço alto: a angústia, a vida dilacerada. A chama que ilumina mais, dura menos. Amy Winehouse não foi a primeira e provavelmente não será a última artista genial a entrar em um processo autodestrutivo. Um processo de total perda de esperança resultando na busca deliberada pela morte. No Romantismo Alemão vários escritores e filósofos falaram sobre o peso da genialidade. Schelling coloca que o gênio é capaz da mesma intuição criadora do Espírito Absoluto. Schopenhauer nos fala da dor de ser gênio. Nietzsche, como Schiller, defende a genialidade artística como o único objetivo digno da vida humana. A vida é arte e cabe a nós desenvolvermos essa arte. Os poetas malditos, as estrelas do rock e do jazz celebraram esta festa, a vida, mesmo que, ao final, não haja mais vida alguma. Diante de um fenômeno midiático como Amy Winehouse, como podemos compreender toda essa reflexão filosófica sobre arte, vida, genialidade e morte?

Palvras-chave: Filosofia. Amy Winehouse. Genialidade. Romantismo Alemão.
\end{abstract}

Tudo o que posso ser para você é a escuridão que já conhecemos

(All I can ever be to you is a darkness that we knew).

Amy Winehouse (1983-2011) começa assim a sua composição "Lágrimas secam por si próprias" (Tears dry on their own), revelando, tal como um trovador medieval ou, quem sabe, um repentista brasileiro, os segredos de sua alma. Ela nasceu em uma área suburbana de Southgate, bairro de Londres, numa família judia de quatro pessoas e de tradição musical ligada ao jazz. Seu pai, Mitchell Winehouse, era motorista de táxi e sua mãe, Janis, farmacêutica. Aos 20 anos lançou seu primeiro álbum, Frank (2003), que alcançou relativo

*Pontifícia Universidade Católica de Minas Gerais - PUC Minas. 
sucesso. Pouco depois, estoura com o álbum Back to black (2006). Ambos fazem referência aos namorados de Amy, Frank e Blake. Aos 23 anos, Amy já era uma garota rica, bem sucedida e extremamente talentosa. No entanto, tal como na Crônica de uma morte anunciada (1981) de Gabriel García Marquez, todos já esperavam a sua morte prematura. As pessoas pagavam para ir aos seus shows não para ouvir suas canções e narrativas do cotidiano, mas para vê-la caindo, esquecendo as letras das músicas, passando mal.

O que está acontecendo? Por que ocorre um comportamento autodestrutivo entre jovens e artistas? Por que tanto desespero? Coloquei no título a expressão casa dos mortos fazendo uma referência a Dostoiévski (1821-1881), que escreveu Recordações da casa dos mortos (2010) em 1862 falando de uma prisão na Sibéria para a qual eram mandados prisioneiros indesejáveis, que nunca mais deveriam voltar, ou seja, era uma prisão de mortos-vivos, homens sem nenhuma esperança de saírem daquele lugar, vivendo uma vida da qual não se podia esperar mais nada, a pura loucura. No entanto, segundo Dostoievski, aqueles homens se mantinham firmes na determinação de viver e continuavam sonhando um dia "escapar" daquela prisão. Segundo o Romantismo Alemão, o gênio artístico também vai para a casa dos mortos, local do qual já não tem nenhuma esperança de sair e a única forma de "escapar" é através da própria morte. Amy Winehouse expressa isso muito bem em sua música "Love is a losing game", que em um primeiro momento poderíamos traduzir por amar é um jogo de azar, mas se nos aprofundarmos no sentido da música veremos que a melhor tradução seria amar é um jogo que causa perdas: "como eu queria nunca ter jogado./ Oh, que estrago nós fizemos/. E agora o lance final/. O amor é um jogo que causa perdas". ("Why do I wish I never played./ Oh, what a mess we made/. And now the final frame/. Love is a losing game".) (WINEHOUSE, 2003).

O gênio é aquele que perde tudo, até a si mesmo. Enquanto esperamos "ganhar" algo, continuamos jogando com a esperança de compensar nossas perdas. Mas quando se percebe que não há mais nada a ganhar, então viver e morrer se tornam a mesma coisa. Provavelmente, Amy não tinha mais medo da morte, por isso não via necessidade de se submeter a uma reabilitação, por isso ela não queria ser ajudada. Ela sabia que a resposta não estava nas drogas ou no álcool, mas também sabia que as respostas não estavam em lugar nenhum: “Tentaram me mandar pra reabilitação/. Eu disse não, não, não/. Não aprendi muito na escola/, mas sei que as respostas não estão no copo de cachaça” ("They tried to make me go to rehab/, but I Said “no, no, no"/. I didn't get a lot in class/, but I know it don't come in a shot glass"). (WINEHOUSE, 2003). 
Criar também significa destruir. O novo só surge dos escombros do antigo. Ora, estávamos falando de perdas. Viver é caminhar em direção à morte e neste caminho vamos perdendo as coisas que amamos até chegarmos à perda final. Ao gênio artístico é colocado um peso adicional: perder o passado para criar o novo, estar permanentemente submetido a um processo de abandono e pressão para criar coisas novas. Nesta situação o recurso ao álcool torna-se compreensível (não justificado). A embriaguez do álcool e das drogas leva o artista a descobrir novas formas de percepção, novas experiências sensoriais. Lembremos do livro As portas da percepção (1981) escrito em 1954 por Aldous Huxley. Nele o autor relata as suas experiências alucinatórias quando tomou mescalina. O título, que inspirou também o nome do grupo de rock The Doors de Jim Morrison, provém de uma citação do artista romântico inglês William Blake (1757-1827): "Se as portas da percepção estivessem limpas, tudo apareceria para o homem tal como é: infinito" ("If the doors of perception were cleansed everything would appear to man as it is, infinite").

É claro que álcool e drogas não são pré-condições para a criação artística, mas veremos adiante como o Romantismo Alemão, juntamente com o movimento francês dos poetas malditos, predispõe o artista a fazer essa relação. Além disso, álcool e drogas possuem outra semelhança com a arte. Ambas são remédios contra as angústias da vida. O trabalho do artista e Amy era um bom exemplo disso, é revelar as angústias existências que as pessoas comuns guardam a sete chaves para suportarem viver socialmente tranqüilas as suas vidas cotidianas. Nietzsche no Nascimento da tragédia fala de uma antiga lenda grega que sintetiza bem essas angústias. $\mathrm{O}$ rei Midas perseguiu durante longo tempo na floresta o velho sátiro Sileno, companheiro de Dionísio, sem conseguir alcançá-lo. Quando afinal pôde pegá-lo, perguntou-lhe o rei qual era a coisa que o homem devia preferir a qualquer outra e estimar acima de tudo. Imóvel e obstinado, o demônio permanecia mudo; mas ao fim, forçado pelo vencedor, pôs-se a rir e deixou escapar estas palavras:

Raça efêmera e miserável, filho do acaso e da dor, por que me forças a revelar o que fora melhor que não conhecesses jamais? O que deves preferir a tudo é para ti impossível: é não ter nascido, não ser, é ser nada. Mas depois disso o que podes desejar de melhor é morrer depressa (NIETZSCHE, 1992, p. 36).

Nietzsche fala do apolíneo e do dionisíaco como duas forças fundamentais para a arte. Apolo (razão) é a força da ordem e da forma. Dionísio (embriaguez) 
é a força bruta da natureza, desordenada e sem forma. Lidar com forças tão tremendas não é fácil. Deixar prevalecer o apolíneo é ter uma arte bela (harmoniosa e simétrica), mas sem vida. Deixar prevalecer o dionisíaco é ter uma arte viva, mas louca e sem medida.

"Ele não deixou tempo para arrependimento/. Eu irei voltar ao luto/a morte/ ao Blake" ("He left no time to regret/. I'll go back to black") (WINEHOUSE, 2003). Tal como Chuck Berry, as letras de Winehouse são autobiográficas. São relatos de um cotidiano não muito exemplar, mas real, cercado de vícios e de pessoas de carne e osso. Chuck Berry é um dos pais do rock on roll, gíria utilizado pelos negros americanos para se referir ao ato sexual (balançar e rolar). A partir do Blues e do Soul, Berry inventa uma nova maneira de tocar que se tornará um fenômeno cultural e mais do que uma maneira de tocar, irá se tornar uma nova atitude perante a vida. Surge uma nova estética. Aisthésis, em grego, significa sensibilidade, só que hoje, a palavra sensibilidade está mais associada à percepção física e sensorial, já a sensibilidade estética está carregada de sentimento, de emoção, de alma. Winehouse é atraída pelo soul, pelo Blues e pelo Jazz, ou seja, pela Black music, a música negra americana: vamos voltar ao Black (Back to black). Mas black é também o luto, a morte. E a referência ao seu namorado Blake é evidente. Todos nós estamos caminhando para a morte, no entanto, Amy faz uma relação interessante da morte com o amor; caminhar para o amor é também caminhar para a morte. Ambos, amor e morte, remetem ao sentimento de perda. Normalmente tentamos compensar as perdas da morte com os ganhos do amor, afinal de contas, o amor é mais forte que a morte. Mas se amor e morte se equivalem, então não se ganha nada. A vida em sociedade é mera convenção insensata. Passa a ser insuportável para o artista viver um vida com a qual não se concorda: "Eu trapaceei a mim mesmo./ Como eu sabia que eu iria fazer./ Eu te disse que eu era encrenca/ Você sabe que eu não presto." ("I cheated myself/. Like I knew I would./ I told you I was troubled./ You know that I'm no good.”) (WINEHOUSE, 2003).

O que acontece com os artistas geniais? Rimbaud, Lautréamont, Ginsberg, Kurt Colbain, Raul Seixas, Elvis Presley, Jean Genet, Janis Joplin, Antonin Artaud, Edgar Allan Poe, Augusto dos Anjos. Os franceses cunharam o termo poetas malditos (poète maudit) para designar os poetas que mantêm um estilo de vida que pretende ser diferente do resto da sociedade, considerada como um meio alienante que aprisiona os indivíduos nas suas normas e regras excessivas. Os poetas buscam, agora, viver de forma coerente com o que pensam, com a sua arte. E o que significa isso? 
Frejat na música "O poeta está vivo" diz que "O poeta não morreu,/ foi ao inferno e voltou./ Conheceu os jardins do Éden e nos contou./ Mas quem tem coragem de ouvir./ Amanheceu o pensamento,/ que vai mudar o mundo/ com seus moinhos de ventos." (BARÃO VERMELHO, 1990). O poeta está vivo, com seus moinhos de vento a impulsionar a grande roda da história. O poeta é aquele que desce aos infernos para depois nos contar o que viu, alimentando em nós os nossos sonhos que irão mudar o mundo. "Descer aos infernos" significa vivenciar de forma radical os sentimentos mais profundos e terríveis do ser humano. A arte não é mais uma mera representação, mas passa a ser uma apresentação da própria vida. Um bom exemplo disso é Arthur Rimbaud (1854-1891), que escreveu em 1871 para Georges Izambard uma carta que ele mesmo chamou de carta de um vidente (du voyant).

Le poète se fait voyant par un long, immense et raisonné dérèglement de tous les sens. Toutes les formes d'amour, de souffrance, de folie; il cherche lui-même, il épuise en lui tous les poisons, pour n'en garder que les quintessences. Ineffable torture où il a besoin de toute la foi, de toute la force surhumaine, où il devient entre tous le grand malade, le grand criminel, le grand maudit, - et le suprême Savant! - Car il arrive à l'inconnu! - Puisqu'il a cultivé son âme, déjà riche, plus qu'aucun! Il arrive à l'inconnu; et quand, affolé, il finirait par perdre l'intelligence de ses visions, il les a vues! Qu'il crêve dans son bondissement par les choses inouïes et innommables: viendront d'autres horribles travailleurs; ils commenceront par les horizons où l'autre s'est affaissé!' (RIMBAUD, 1982, p. 36 )

Rimbaud fala de vidência não no sentido de ver o futuro, mas no sentido de ver o presente tal como ele é. Ver os sentimentos mais profundos da alma humana. E se há sentimentos bonitos nestas profundezas, há com certeza sentimentos que nos horrorizam. Sentimentos, que tal como o retrato de Dorian Gray, gostaríamos de manter escondidos de todos, inclusive de nós mesmos. E cabe ao poeta, nesta perspectiva maldita, revelar os horrores da

\footnotetext{
$1 \mathrm{O}$ poeta se torna vidente por um longo, imenso e sensato desregramento dos sentidos. Todas as formas de amor, de sofrimento, de loucura, ele busca a si mesmo, ele esgota todos os venenos em si mesmo, para manter apenas a quintessência. Inefável tortura, onde ele precisa de toda a fé, toda a força sobre-humana, onde ele se torna entre todos o grande doente, o grande criminoso, o grande maldito - e o supremo Sábio! - Pois ele chega ao desconhecido! - Desde que ele cultivou sua alma, já rica, mais do que qualquer um! Ele chega ao desconhecido, e quando, enlouquecido, ele acabaria por perder a inteligência de suas visões, vê-los! Deixá-lo morrer em seus limitados sentidos através de coisas incríveis e inomináveis: vêm outros horríveis trabalhadores e eles começam com os horizontes onde o outro entrou em colapso!
} 
alma e, para isso é preciso vivê-los, implantar verrugas no próprio rosto, e não apenas imaginá-los.

Podemos situar essa nova perspectiva estética, essa nova tarefa do poeta, em dois momentos: o Romantismo Alemão e o Rock on Roll.

O Romantismo Alemão foi um movimento artístico-filosófico surgido na Europa do século XVIII. É um movimento de revolta contra o Iluminismo, embora paradoxalmente mantivesse vários elementos do próprio Iluminismo. Os românticos consideravam o pensamento científico-iluminista, cujo modelo era a física newtoniana, como muito estreito. A ideia de uma vida medida matematicamente e geometricamente era reduzir os homens a galinhas que só conseguiriam enxergar em torno dos próprios pés. Nada contra as ciências naturais, mas era preciso ir além. Se Kant preocupou-se em demarcar os limites do conhecimento humano, agora era preciso expandi-los novamente em direção ao infinito. Se os iluministas cultuavam a luz do dia, então os românticos cultuarão a escuridão da noite. Os românticos vão falar de uma dimensão oculta do ser humano que determina a sua dimensão visível (o inconsciente, embora eles não tenham usado especificamente esta palavra). Podemos citar três romances como exemplo da exploração deste lado noturno (dos sonhos) da alma humana. Frankenstein, escrito em 1816 por de Mary Shelley; Drácula, escrito em 1897 por Bram Stocker e O médico e o monstro, escrito em 1886 por de Robert Louis Stevenson.

Segundo os românticos, o espírito humano é maravilhosamente criativo, capaz não só de penetrar nos mistérios, mas também de os representar e dar vida, em obras de gênio original. O artista tornou-se o ideal de homem. Para Shelley, por exemplo, o poeta era mais do que humano, um visionário que participava do Eterno, levantando o véu do mundo oculto da beleza. Do mesmo modo, para Schelling, o artista, sozinho entre os homens, conhecia o Absoluto por intuição direta e, em conseqüência, apresentava no seu trabalho uma infinidade que nenhuma compreensão finita podia revelar completamente. A criação artística não é resultado de um planejamento racional, mas de um processo natural e inconsciente. Para Baumer, a

doutrina romântica do gênio não pode ser completamente compreendida sem se fazer referência ao inconsciente. De fato, a antropologia romântica presumia, em geral, a existência de um espírito "irracional" ou inconsciente. (...) O inconsciente era usado para explicar não só o processo criativo, mas também o "lado noturno" da vida humana, o mundo dos sonhos, os 
monstros e as aparições, era mais um conceito metafísico do que científico. $\mathrm{O}$ artista era normalmente representado como uma planta crescendo inconscientemente, ou como um meio através do qual o Eterno atuava e se expressava. Alguns, como o artista e poeta William Blake acreditavam no automatismo poético. "Escrevi este Poema", diz Blake no seu Milton "espontaneamente... sem premeditação e mesmo contra a minha vontade" (BAUMER, 1990, p. 40 -destaques nossos).

Certamente que explicar, ainda mais em termos racionais, a criação artística é uma tarefa árdua, mesmo para os dias de hoje, o que se dirá no século XVIII e XIX. No entanto, há um elemento novo, surpreendente e fundamental no Romantismo Alemão: a afirmação da própria subjetividade. Maquiavel, Descartes e outros já haviam problematizado a questão antes dos românticos, mas há aqui uma diferença fundamental. A subjetividade foi pensada desde o Renascimento com relação ao problema do conhecimento. A preocupação de Descartes era com o sujeito do conhecimento científico, aquele que faz ciência. Alguém poderia argumentar que os românticos também estavam preocupados com o sujeito que faz ciência. Só que aqui temos dois conceitos bem diferentes do que seja ciência.

Podemos considerar Kant como o filósofo que consolidou o conceito de ciência dos Iluministas e de outros filósofos anteriores, como Maquiavel e Descartes. Para Kant, a ciência deve produzir conhecimentos capazes de serem testados empiricamente. Kant não é um empirista, pois considera as experiências científicas como não intuitivas, ou seja, não são nem espontâneas e nem óbvias, por isso precisam ser constituídas (configuradas) a partir de princípios racionais a priori (anteriores à experiência). A razão constrói o conhecimento científico, que por sua vez, precisa passar pelo critério do teste empírico. A experiência científica não está na origem do conhecimento, mas no seu final. Kant critica os vôos da razão metafísica como não científicos. Assim, temos um conceito de ciência em Kant restrito aos limites da experiência possível. Não é difícil perceber que grande parte dos fenômenos da vida humana está fora deste conceito de ciência.

Os românticos vão operar com um conceito ampliado de ciência: saber acerca da totalidade (Hegel: a verdade está no todo). A ciência para os românticos não se restringe ao empiricamente verificável, pois várias verdades, talvez as mais importantes, só podem ser alcançadas pela intuição e pelo raciocínio. A natureza e a vida humana são totalidades que não podem ser testadas empiricamente. 
O sujeito romântico é voltado para si mesmo, para seus sentimentos, suas angústias, suas obscuridades. $\mathrm{O}$ mergulho na subjetividade não é mais em busca de um conhecimento científico, mas da compreensão do espírito humano em toda a sua infinita capacidade. Sentimentos, medos, sonhos e esperanças são componentes essenciais da subjetividade romântica. Surgem no Romantismo as narrativas das histórias pessoais de pessoas comuns, que não querem servir de exemplo para ninguém, mas necessitam desesperadamente afirmar o próprio eu. Por isso encontramos o recurso do diário como estratégia literária. A alma particular é tão importante quanto a das grandes figuras da humanidade, mesmo porque a alma finita é uma parte da alma infinita do todo. Aqui temos uma característica essencial do gênio romântico. Ele, ao mergulhar em sua própria alma, encontra a alma da humanidade. Em momento algum os românticos pretendem uma individualização radical do espírito humano, pelo contrário, os conceitos de totalidade e infinito são essenciais para eles. Assim, esse mergulho na própria subjetividade significa encontrar o todo/infinito que habita dentro de nós, seres finitos. Segundo Schelling,

tanto mais apto estará o produtor [artista/criador] a expor outras coisas que não ele próprio, e mesmo a distanciar-se inteiramente de sua individualidade (...). Mas o produtor não se iguala, também nisto, àquele de quem ele é a emanação? Pois também aquele, ou seja, Deus, acaso revelou em algum lugar do mundo sensível a beleza tal como está nele mesmo, e não dá, em vez disso às idéias das coisas, que estão nele, uma vida própria e independente, fazendo-as viverem como almas de corpos singulares? E, aliás, não é justamente por isso que toda obra cujo produtor é o conceito eterno do indivíduo tem uma dupla vida, uma independente em si mesma, outra naquele que a produz? (SCHELLING, 1979, p. 64).

O gênio artístico criador é capaz de reproduzir dentro de si o próprio impulso da criação divina. Da mesma forma que a natureza, a obra de arte do gênio tem vida própria tornando-se independente do seu criador. O romantismo inaugura uma nova concepção da criação artística: não se trata mais de habilidade ou domínio técnico. O artista criador deve ser, antes de tudo, um demiurgo, uma nova força cósmica inata, independente da cultura, que decifra de maneira intuitiva e direta o livro da natureza. E neste processo, a criação é o fruto da espontaneidade, pois que surge inteira no ato de criar. No artista vive qualquer coisa mais poderosa do que ele próprio, um poder que o impele, que, por seu intermédio, cria qualquer coisa de infinito, de eterno. Está submetido a este 
poder, como está ao seu destino. $\mathrm{O}$ artista tem aquilo que o homem comum não tem: um destino próprio e interior. $\mathrm{O}$ valor da obra passa a residir em algo que não esta nela objetiva e formalmente, e sim na subjetividade do autor. Uma obra de arte é inesgotável, contém, na sua perfeição hermética, mais do que aquilo que o artista pôde conscientemente introduzir. Mas o que é aquilo que nele cria inconscientemente? O próprio infinito.

O Romantismo Alemão não apenas descobre uma nova dimensão da subjetividade, ele também inventa uma nova percepção estética da subjetividade. As pessoas passam a perseguir o caminho do romantismo para alcançar a sua subjetividade. Não se trata de simplesmente descobrir algo que já estava ali, mas de procurar algo que você não tem certeza de estar ali, no entanto, você quer tanto encontrá-lo que acaba encontrando-o. As pessoas passam a querer algo que antes elas nem sequer sonhavam existir. Muitos pais de famílias proibiam suas filhas de lerem livros como Madame Bovary de Flaubert por temerem uma mudança de comportamento em suas jovens donzelas. A ideia de uma literatura capaz de despertar/criar novos sentimentos e provocar mudanças drásticas na vida das pessoas é nova e revolucionária, e estava totalmente sincronizada com as rápidas mudanças sociais provocadas pelo capitalismo.

O Rock on roll simboliza bem a retomada de alguns dos ideais do Romantismo Alemão, com uma diferença fundamental: o rock nasce no contexto de um capitalismo tardio, ou seja, um capitalismo já consolidado e agora preocupado em resistir aos ataques dos movimentos revolucionários. Embora Amy Winehouse não seja uma cantora de rock, a comparação nos serve aqui porque estamos preocupados não com estilos musicais, mas com uma educação estética capaz de formar a percepção de mundo dos jovens e Winehouse se insere nesta perspectiva.

O rock é um fenômeno paradoxal (como o romantismo) já na sua origem. Ele surge como um fenômeno de contracultura, e a cultura a qual ele se contrapunha era o capitalismo. No entanto, o rock surge como uma estratégia capitalista para explorar um novo mercado emergente no final dos anos 1940 e início dos anos 50: os adolescentes. Antes, as pessoas eram separadas em adultos e não-adultos. As crianças eram consideradas como pequenos adultos, que somente precisavam de algum rito de passagem para entrarem imediatamente na idade adulta. A ideia de uma fase de transição de vários anos entre a infância e a fase adulta era totalmente absurda. Até termos uma nova situação social na qual a formação profissional só terminava em torno 
dos 24 anos, o que gerava a situação de pessoas que não eram mais crianças e, no entanto ainda não eram adultas. A adolescência é então inventada pelo capitalismo para dar conta daqueles jovens que ainda dependiam dos pais, pois ainda estavam estudando na Faculdade e, no entanto já se sentiam livres e queriam viver a própria vida e, mais importante, queriam consumir coisas específicas para eles. O rock nasce como uma estratégia de mercado, embora se posicionasse contra esse mesmo mercado. As estrelas do rock ganharam e ganham muito dinheiro. Como explicar esse paradoxo?

Podemos achar uma boa explicação no livro Dialética do esclarecimento (1986), escrito em 1947 por Adorno e Horkheimer. Neste livro, eles apresentam o conceito de indústria cultural. A arte passa a ser vendida como mercadorias. A vantagem para o capitalismo é que junto com a arte também se vendem idéias. A arte (cultura), com o seu poder de provocar comportamentos, passa a ser industrializada, domesticada e utilizada para vender comportamentos. Já que os adolescentes são rebeldes, então a rebeldia é oferecida a eles. O rock é uma música marcada pela rebeldia, por estabelecer um contato intimo com a alma do jovem. Não interessa se o cantor é conservador, a música é revolucionária. Assim, mesmo um sexagenário como Mick Jagger é considerado “jovem”, pois ele continua a "conversar" com os adolescentes; ele continua a transmitir o hino da juventude, que é não esqueçam seus sonhos, suas promessas. O tempo do rock é o tempo da rebeldia, dos sentimentos desmedidos, loucos, intensos. A chama que ilumina mais é a que dura menos. Dentro desta estratégia surge o junkie, o estereótipo do drogado genial, revoltado contra o sistema, inconformado com as regras sociais. Esses artistas passam a vender mais do que os normais. Que paradoxo terrível: o capitalismo lucra com a revolta contra ele próprio.

Mas, se o rock e outras formas de arte vendem a rebeldia para a juventude com o objetivo oculto de tornar o jovem um rebelde domesticado, isso não significa que não tenhamos grandes artistas, que seguindo o espírito do gênio romântico vivam com tamanha intensidade a sua arte, que terminam por entrar em um processo auto-destrutivo de criação radical no qual o amor não é mais forte que a morte, mas apenas tão forte quanto ela. Assim as perdas do amor se equivalem as perdas da morte fazendo com que o estar vivo não se torne mais atraente do que o estar morto. Penso que Amy Winehouse pode ser classificada entre esses gênios. É ainda muito cedo para avaliar a genialidade dela, mas não é este o ponto que estamos discutindo. A questão é a seguinte: as músicas e as letras dela conduziam as profundezas infernais da alma humana: 
a incompreensão dos outros, a falta de amor, os excessos, a simplicidade. Tudo isso estava lá. E isso estabelecia um canal de comunicação direta com todos aqueles que ainda buscam a rebeldia e o inconformismo, uma vida vivida intensamente a cada segundo, mesmo que essa busca se reduza a um rótulo musical. Na realidade, todos nós gostaríamos de viver a vida como se ela fosse uma obra de arte, só que não podemos, mesmo porque a genialidade é algo que não se escolhe. Mas se não podemos fazer arte, não significa que não podemos ter arte. Por isso necessitamos tanto de pessoas como Amy Winehouse, mesmo que isso signifique sugá-las até a morte.

\begin{abstract}
This article discusses geniality in a German Romanticism perspective, focusing on the carrier of singer Amy Winehouse. Winehouse was not the first and probably not the last artist to enter a self-destructive process what seems to be a deliberate pursuit of death. In German Romanticism various writers and philosophers talked about the burden of the genius. Schelling puts that genius is capable of the same creative intuition of the Absolute Spirit. Schopenhauer mentions the pain of being a genius. Nietzsche, Schiller defends the artistic genius as the only goal worthy in human life.
\end{abstract}

Key words: Philosophy. Amy Winehouse. German Romanticism. Genius.

Referências

ADORNO, Theodor W.; HORKHEIMER, Max. Dialética do esclarecimento: fragmentos filosóficos. 2. ed. Rio de Janeiro: Jorge Zahar, 1986.

BAUMER, Franklin. O pensamento europeu moderno. V. II. Lisboa: Edições 70, 1990.

BARÃO VERMELHO. O poeta está vivo. Álbum Na calada da noite. WEA, 1990.

DOSTOIÉVSKY, Fiodor. Recordações da casa dos mortos. SP: Nova Alexandria, 2010.

HUXLEY, Aldous. As portas da percepção e Céu e inferno. 10. ed. Porto Alegre: Globo, 1981. 
MARQUEZ, Gabriel García. Crônica de uma morte anunciada. RJ: Record, 1981.

NIETZSCHE, Friedrich. O nascimento da tragédia, ou Helenismo e pessimismo. São Paulo: Companhia das Letras, 1992.

RIMBAUD, Jean-Arthur. Uma temporada no inferno e Iluminações. Tradução de Lêdo Ivo. Rio de Janeiro: Francisco Alves, 1982.

SCHELLING, Friedrich Wilhelm Joseph Von. Obras escolhidas. São Paulo: Abril Cultural, 1979 (Os Pensadores).

WHINEHOUSE, Amy. Frank. Album. Jamaica: Island Record, 2003.

WHINEHOUSE, Amy. Back to black. Album. Jamaica: Island Record, 2003. 